\title{
Bases para el establecimiento de vínculos comerciales entre el Río de la Plata y el Brasil a fines de la etapa colonial
}

\author{
Hernán Asdrúbal Silva \\ Universidad Nacional del Sur y CONICET \\ Bahía Blanca, Argentina
}

\begin{abstract}
El presente trabajo tiene por objeto estudiar las disposiciones y las condiciones conducentes al establecimiento de vínculos económicos entre el Río de la Plata y el Brasil bajo formas legales que, aunque también escondieron muchos fraudes, fueron determinantes para realizar un fluido y continuo tráfico intercolonial.
\end{abstract}

\section{La apertura del tráfico negrero}

En la última década del siglo XVIII, dos importantes disposiciones en materia comercial, con sus correspondientes medidas complementarias, generaron las condiciones para el establecimiento de vínculos económicos entre el Río de la Plata y el Brasil bajo formas legales. Me refiero en primer lugar a la libre trata de negros y posteriormente a la apertura más amplia que se produce con la autorización para comerciar, "por vía de ensayo", con colonias extranjeras. El interés por incorporar a las colonias mano de obra abundante y barata, motivó la implementación de medidas más liberales en materia de tráfico negrero.

Las ideas fisiocráticas que propulsaban el desarrollo de la actividad agrícola fueron un importante incentivo y, en 1789, se disponía el libre comercio de esclavos a Cuba, Santo Domingo, Puerto Rico y Venezuela. Medida ésta que, en 1791, se extiende — entre otras regiones - al Río de la Plata.

Si bien la real cédula que otorga a la región platina los privilegios acordados a otras zonas data del 24 de noviembre de $1791,{ }^{1}$ ya para entonces se habían otorgado permisos especiales a Nicolás del Acha, comerciante de Buenos Aires, y a Manuel Pereyra, portugués residente en Sevilla, para introducir 1.000 negros cada uno desde el Brasil. Ambas resoluciones, del 7 de junio de 1791, tenían como fundamento la necesidad de fomentar

1 Documentos para la Historia Argentina, Tomo VII, Comercio de Indias, Consulado, Comercio de Negros y de Extranjeros (1791-1809). Buenos Aires, 1916, pág. 4 y ss.

Tomo LIV, 2, 1997 
la agricultura y el desarrollo de la ganadería. ${ }^{2}$ Además, otra real orden de septiembre, preanunciaba la disposición general, reactualizando un permiso para que el comerciante local Tomás Antonio Romero ingresara otros 1.000 esclavos desde puertos brasileños, bajo "las franquicias y gratificaciones" expedidas en $1789 .{ }^{3}$

La implementación del nuevo sistema incentivó la introducción de esclavos, con una importante participación de navíos extranjeros, no debiéndonos extrañar que gran parte de las expediciones negreras procedieran del Brasil, desde donde se podían traer los negros en mejores condiciones físicas.

El efecto fue rápido, sintiéndose particularmente en 1793. En 1792, 660 negros eran desembarcados de 4 navíos portugueses y 1 español, produciéndose hasta 1796 las siguientes introducciones: ${ }^{4}$

\begin{tabular}{lccc} 
Año & Embarcaciones & Cantidad de esclavos \\
\hline 1793 & 4 Españolas & 810 \\
& & 6 Extranjeras & 1.317 \\
& Total & 10 & 2.127 \\
\hline 1794 & & 3 Españolas & 421 \\
& & 5 Extranjeras & 757 \\
& Total & 8 & 1.178 \\
\hline 1795 & & 3 Españolas & 466 \\
& & 6 Extranjeras & 908 \\
& Total & 9 & 1.374 \\
\hline 1796 & & 4 Españolas & 784 \\
& & 5 Extranjeras & 566 \\
& Total & 9 & 1.350 \\
\hline
\end{tabular}

El puerto de Montevideo fue la base del tráfico negrero regional, constituyéndose este comercio en otro de los factores de rivalidad entre las dos bandas del Río de la Plata. Los esclavos no sólo encontraron colocación en el área rioplatense, sino también en Chile y Perú.

2 Ibídem, Tomo VI, Comercio de Indias, Comercio Libre (1778-1791). Buenos Aires, 1915, págs. 485-86.

3 Ibídem, pág. 487. 
Nuevas autorizaciones reales fueron dando un mayor margen de acción a los esclavistas. A la real orden de 1791, se le suma en 1792 la ampliación del plazo de permanencia en puerto de las naves extranjeras de 8 a 40 días, aspecto importante para incrementar no sólo los nexos entre los foráneos y los comerciantes locales, sino también con sectores de la población. Es justamente Romero uno de los principales esclavistas que generan y mantienen las relaciones comerciales con el Brasil. Baste decir que, entre 1793 y 1795, introdujo 1.614 piezas desde las colonias portuguesas, 354 transportadas en barcos españoles y 1.260 en portugueses. ${ }^{5}$

\begin{tabular}{ccccc} 
Año & Barco & Nombre & Nac. Cantidad \\
\hline 1793 & $\mathrm{C}$ & Ntra.Sra. del Carmen y Sta. Ana & $\mathrm{P}$ & 276 \\
1793 & $\mathrm{Z}$ & Buen Jesús de los Pasos & $\mathrm{P}$ & 216 \\
1793 & $\mathrm{~B}$ & Ntra.Sra.del Carmen (a. La Oliva)* & $\mathrm{E}$ & 45 \\
1793 & $\mathrm{Z}$ & Ntra.Sra.de la Concepción & $\mathrm{P}$ & 162 \\
& & y Sr. de las Puertas & & \\
\hline 1794 & $\mathrm{Z}$ & Ntra. Sra. de la Concepción & $\mathrm{P}$ & 132 \\
& & y San Antonio & & \\
1794 & Bn. & El Buen Jardín & $\mathrm{E}$ & 235 \\
1794 & Bn. & Ntra. Sra. de la Piedad & $\mathrm{P}$ & 247 \\
1794 & $\mathrm{~B}$ & Ntra.Sra.del Carmen (a. La Oliva) & $\mathrm{E}$ & 44 \\
\hline 1795 & Bn. & Ntra. Sra. de la Piedad & $\mathrm{P}$ & 83 \\
1795 & $\mathrm{Z}$ & Ntra. Sra. de Guía & $\mathrm{E}$ & 30 \\
1795 & Bn. & Madre de los Hombres & $\mathrm{P}$ & 137 \\
\hline
\end{tabular}

T (Tipo de barco) = B: Balandra; Bn: Bergantín; C: Corbeta y Z: Zumaca.

Nacionalidad = E: Española; P: Portuguesa.

* a. $=$ alias

Cabe acotar que esta presencia de Romero en el trato esclavista con Brasil, se combinó con el realizado con África, desde donde, con gran riesgo logró en 1793 introducir 426 negros de los 542 que había embarcado en Guinea. ${ }^{6}$ Actitud esta que le valió un largo elogio del virrey Arredondo,

4 Archivo General de Indias (en adelante, AGI), Buenos Aires, 346.

5 Archivo General de la Nación, Argentina (en adelante, AGN), IX-18-8-11.

6 Galmarini, H. R.: "Comercio y burocracia colonial. A propósito de Tomás Antonio Romero", en Investigaciones y Ensayos, N. ${ }^{\circ}$ 29, Buenos Aires, 1980. pág. 392. 
quien luego de quejarse de la "inacción" de otros españoles, lo denomina "hombre de posibles y de bizarro espíritu para negocios grandes":

"De manera que, a no haber sido por los singulares bríos de este español [Tomás Antonio Romero], nunca hubiera tenido el Rey la complacencia de ver que hay por lo menos un vasallo que piensa y obra según sus reales miras en negocio de tanto costo y de tantas aventuras. A la verdad no debe ser el comercio de negros cosa tan llana para los españoles, cuando estamos observando que hasta el presente no ha entrado un solo barco con negros, en Montevideo ni Buenos Aires, traído derechamente del África por cuenta de nuestros comerciantes europeos, entre los cuales cuento a los animosos catalanes...".

Es interesante observar cómo este comerciante, con sus actitudes, aparece como un caso típico en esta etapa de profundas contradicciones, enfrentamientos ideológicos y puja de intereses. Mientras en esta Memoria virreinal de marzo de 1795 se exaltaba su empuje empresarial, en la del virrey anterior [febrero de 1790], el marqués de Loreto se congratulaba de que el rey hubiera aprobado sus providencias "contra el asentista D. Tomás Antonio Romero, que se había propuesto franquear estos puertos a la bandera que él eligiese para otro negociado de negros". 8

Junto a Romero actuaron otros esclavistas, que no siempre vieron favorecidas sus actividades. Tal fue el caso de José Fernández de Castro que, en 1794, luego de llegar a Bahía, por orden del capitán general no pudo embarcar los negros que tenía comprados. Situación esta que no impidió la transacción, ya que los esclavos fueron dirigidos a Río Grande y desde allí por tierra a Montevideo. ${ }^{9}$

Tanto esta apertura, como las que llegarán antes y después de la guerra de 1796, traerán aparejadas intensas discusiones, siendo los argumentos más importantes de la oposición la extracción de metálico y los fraudes cometidos a su amparo. En realidad esto no era nuevo, ya que como señala Corcino Medeiros dos Santos, existían por lo menos dos razones fuertes que habían cimentado las relaciones comerciales entre el Brasil y el Plata. Por un lado se encontraba la necesidad que Portugal tenía de plata española y por otro, el requerimiento de esclavos, géneros de Brasil y manufacturas de Europa. Esto, agrega, fue lo que hizo que muchas veces los gobernantes de Buenos Aires y de Río de Janeiro, cuando no participaban directamente en los negocios, fingieran ignorarlos. ${ }^{10}$

7 Memorias de los Virreyes del Río de la Plata, Buenos Aires, 1945, pág. 393.

8 Ibídem, pág. 255.

9 AGN, IX-18-8-11

10 Santos, C. M. dos: Relaçoes comerciais do Río de Janeiro com Lisboa (1763-1808), Río de Janeiro, 1980, pág. 79. 
COMERCIO ENTRE RÍO DE LA PLATA Y BRASIL A FINES DE LA ETAPA COLONIAL

VALOR DE LOS EFECTOS Y METÁLICO SALIDOS EN LAS EMBARCACIONES DESTINADAS AL COMERCIO DE NEGROS ${ }^{11}$

\begin{tabular}{llrrrr} 
Año & Nacionalidad & Plata & Frutos & Total & Plata \\
\hline 1793 & Españoles & 20.600 & 4.350 & 24.950 & \\
& Extranjeros & 48.594 & 6.190 & 54.784 & \\
& Total & 69.194 & 10.540 & 79.734 & $86,78 \%$ \\
\hline \multirow{1}{*}{1794} & Españoles & 25.000 & 7.000 & 32.000 & \\
& Extranjeros & 26.940 & 6.060 & 33.000 & \\
& Total & 51.940 & 13.060 & 65.000 & $79,91 \%$ \\
\hline 1795 & Españoles & 209.698 & 1.842 & 211.540 & \\
& Extranjeros & 28.729 & 5.547 & 34.276 & \\
& Total & 238.427 & 7.389 & 245.816 & $96,99 \%$ \\
\hline 1796 & Españoles & 25.000 & 7.000 & 32.000 & \\
& Extranjeros & 28.729 & 5.547 & 34.276 & \\
& Total & 53.729 & 12.547 & 66.276 & $81,06 \%$ \\
\hline
\end{tabular}

Las cifras del quinquenio 1792-1796, fueron utilizadas por Azara para componer un "Cuadro demostrativo del estado de comercio de todos los puertos del Río de la Plata", citado en varios trabajos historiográficos, pero que tiene el problema de promediar los resultados del movimiento mercantil y naviero. De allí que establezca el siguiente cuadro para los "buques salidos para ir a buscar negros": ${ }^{12}$

\begin{tabular}{lr} 
Plata en pesos & 120.276 \\
Valor de productos en pesos & 12.738 \\
\hline Valor total en pesos & 133.014
\end{tabular}

Si bien existen compensaciones por exportaciones de efectos hacia otros destinos, es interesante observar las declaraciones que hace nuestro conocido Romero, con respecto a las cantidades extraídas por las aduanas

11 AGI, Buenos Aires, 346.

12 Azara, F.: Viajes por la América Meridional, Tomo II, Madrid, 1941, págs. 200-201. 
de Buenos Aires y Montevideo, correspondientes a los esclavos conducidos "en embarcaciones portuguesas de las Colonias del Brasil...". Mientras que en 1793 sacaba 34.688 pesos fuertes, de los cuales sólo 4.800 correspondían a cueros y 18.000 a moneda, en 1795 , embarcaba 96.430 pesos fuertes. ${ }^{13}$

Cabe acotar aquí, aunque escape a los alcances y objetivos de este trabajo, la influencia momentánea que tuvo en la extracción de mercancías y dinero, el singular pleito referido a si los cueros podían o no considerarse frutos del país, que llevó a paralizar la salida de los mismos. ${ }^{14}$

\section{Las nuevas autorizaciones}

Los tradicionales nexos con el Brasil, que por lo general no se habían caracterizado por la legalidad o que habían tenido que ser aprobados formalmente para paliar situaciones de extrema necesidad, como las causadas por las guerras, al poco tiempo encontraron una nueva y más amplia medida de legalización. A través de una real orden, el 4 de marzo de 1795, se daba un nuevo y fundamental paso en el proceso aperturista del Río de la Plata, al autorizarse la comercialización "por vía de ensayo", con colonias extranjeras. Cabe agregar que el contenido de tal disposición, era comunicado formalmente por el virrey Melo de Portugal al Tribunal del Consulado, el 2 de enero del año siguiente; aspecto interesante para la consideración de los tiempos que afectan a la aplicación de las decisiones gubernamentales.

Aunque en realidad la resolución real tiene como fundamento una presentación efectuada por el conde de Liniers, con relación a la necesidad de carnes y harinas que tenían "las islas francesas conquistadas por los Ingleses", esta determinación fue fundamental para incrementar el intercambio con diversos puertos del Brasil.

La petición particular del conde de Liniers, para realizar "algunas" expediciones, cuando retornara a Buenos Aires, dará pie a una trascendental medida gubernamental, no sólo por lo que significó desde el punto de vista de los vínculos mercantiles rioplatenses, sino fundamentalmente por su trascendencia en materia de política económica:

13 AGN, IX-18-8-11

14 Tjarks, G.: El Consulado de Buenos Aires y su proyección en la Historia del Río de la Plata. Buenos Aires, 1962, pág. 381 y ss. Studer, E. F. S. de: La trata de negros en el Río de la Plata durante el siglo XVIII, Buenos Aires, 1958, pág. 279. 
"S.M. — dice el documento- considerando que la extracción de frutos y producciones que no sean retorno para España, pueden influir en los progresos de la Agricultura, Comercio y Navegación, como ha sucedido en Caracas con los Ganados y Víveres que llevan a las colonias extranjeras, se ha servido condescender a la instancia del Conde, concediendo al mismo tiempo permiso general por vía de ensayo a todos los que quieran hacer semejantes expediciones...". ${ }^{15}$

A partir de entonces, los comerciantes podrían dirigir a las colonias extranjeras los productos que no tuvieran colocación en la Península, trayendo de retorno frutos (como azúcar, café o algodón), dinero y negros. Es cierto que se aclaraba que tales expediciones deberían de hacerse en buques nacionales y que no podrían introducirse efectos europeos. Aspectos estos que, por necesidad o conveniencia, no tardaron en ser soslayados o burlados. ${ }^{16}$

De acuerdo a la misma resolución se permitía "el retorno desde las [colonias] extranjeras a cualquiera puerto de las nuestras del mismo modo que a Buenos Aires", agregando que desde dichas colonias podrían despacharse a Europa, "en buques de las respectivas naciones", parte de dichos frutos y producciones.

Evidentemente se abrían nuevas posibilidades para las interrelaciones mercantiles de América, pudiéndose señalar con respecto al Río de la Plata que, si bien se establecieron comunicaciones con lugares distantes como Cayena o Mauricio, esta resolución fue fundamental para incrementar el intercambio con diversos puertos del Brasil.

La implementación de este sistema trajo aparejada otra serie de discusiones y enfrentamientos en el marco rioplatense, no sólo por las implicaciones mercantiles derivadas de la incorporación de nuevos centros de intercambio, sino también por los abusos e ilegalidades cometidas a su amparo. Sin embargo, contra la opinión de quienes dudaban sobre los alcances de la real orden de 1795 , o que incluso pretendieron que se coartase directamente este tráfico con los puertos brasileños, el 10 de julio de 1796 se daba otra real orden aclarando la cuestión. En ella se señalaba taxativamente, con respecto a la autorización dada al Río de la Plata para

15 AGN, IX-4-7-8

16 Silva, H. A.: "La españolización de navíos norteamericanos en el Río de la Plata. Entre la legalidad y el fraude". Estudios de Historia Social y Económica de América, Revista de la Universidad de Alcalá, Alcalá de Henares, 1990, T. 6, págs. 65-69, y La portuguización y españolización de navíos en las relaciones entre Brasil y el Río de la Plata. (Finales del siglo XVIII y principios del XIX), elaborado para el "V Congreso de la Sociedad Latinoamericana de estudios sobre América Latina y el Caribe", PROLAM, Programa de pós-graduaçao em integraçao da América Latina, Universidade de Sao Paulo, Brasil. 
comerciar con colonias extranjeras, que el rey había "resuelto que por ahora sea y se entienda general para todas las colonias extranjeras de las islas y continente de América, y particularmente para las portuguesas del Brasil...". ${ }^{17}$

Pese a esta resolución real, durante muchos años continuaron las controversias en torno al tráfico con colonias extranjeras y las presiones para su derogación. No obstante, tanto las alternativas derivadas del enfrentamiento de coyunturas internacionales y regionales difíciles, como el predominio de actitudes aperturistas y el peso de los nexos económicos que se fueron forjando al amparo de las disposiciones metropolitanas coadyuvaron a su mantenimiento. La "vía de ensayo" con que se había iniciado la apertura del tráfico se hizo prolongada, y pese a la expresión "por ahora" que se estampa en la real orden del 10 de julio de 1796, el sistema tiende a consolidarse.

Angel Izquierdo, administrador de la Aduana de Buenos Aires, en un extenso informe al virrey de julio de 1798, avalaba con una serie de preguntas y consideraciones la determinacion metropolitana:

\footnotetext{
“QQué progresos puede calcular el comercio de España con lo que no importa ni exporta en América? ¿Acaso las materias, frutos y producciones de este fecundo suelo en toda su extensión hacen la gruesa contratacion del comercio español en Europa? ¿Por ventura la pérdida de lo que no puede exportar aquél le deja algún provecho? o al contrario ¿no es cierto que las ventajas que saque el colono de lo que pospone el español, trasciende y se comunica por mil modos indirectos en beneficio de éste? Estas verdades son de mucho bulto; y el principio de que se deriban es tan acreditado, que por él sólo se dirige el Gobierno para disponer con destreza y sabia economía los medios y rumbos por donde se haga el Comercio de América con los colonos extranjeros". ${ }^{18}$
}

Los cambios producidos en las reglas que regían el comercio, además de provocar discusiones de orden teórico, llevaron necesariamente a un reacomodamiento del conjunto del giro al exterior. Brasil aportaba azúcar, aguardiente, arroz, almidón, cera, café y añil, etc., sin olvidar a los negros esclavos. De allí que uno de los problemas principales que creó esta apertura comercial, se vinculó a la competencia con otras posesiones españolas de América con las que el Río de la Plata mantenía relaciones comerciales. Tal es el caso de Cuba, con quien por aquellos años se había generado un singular intercambio que, a su vez, promovía el desarrollo de la industria

17 AGN, IX-4-7-8

18 AGI, Buenos Aires, 346. 
saladeril. Las exportaciones de carnes saladas, sebo y otros productos regionales hacia La Habana se incrementaban ${ }^{19} \mathrm{y}$, aunque los retornos no tuvieron el mismo peso, aportaron interesantes proporciones de productos tropicales a estas lejanas tierras australes.

IMPORTACIONES DESDE LA HABANA ${ }^{20}$

\begin{tabular}{lcc} 
& \multicolumn{2}{c}{ Productos } \\
\cline { 2 - 3 } Años & Azúcar/arrobas & Aguardiente/barriles \\
\hline 1794 & 32.842 & 1.744 \\
1795 & 10.646 & 562 \\
1796 & 22.159 & 239 \\
\hline
\end{tabular}

También se traía de Cuba dulce, miel, palo de tinte, maná, cera, palos de acana, arroz y, curiosamente, cacao, aunque desde el Río de la Plata se reexportaba cacao de Guayaquil. Igualmente de Lima y Guayaquil se importaban productos que recibían la competencia brasileña, tales como azúcar y arroz, que también se trajo en ocasiones de La Habana. En 1796 provenían de Lima y Guayaquil 10.975 arrobas de azúcar y 816 de arroz; habiendo llegado en 1794, desde Cuba, 3.380 arrobas de este último producto. Además, a los ingresos por vía marítima se sumaban los trasportados por tierra. Azúcar de las intendencias peruanas próximas al virreinato rioplatense abastecían al Alto Perú y otras remesas desembarcadas en Valparaíso, atravesaban la cordillera a lomo de mula. ${ }^{21}$ Evidentemente, las producciones de retorno encontraron un férreo competidor en el Brasil, cuya cercanía favorecía el intercambio. Situación que sirvió de argumento para impugnar el nuevo sistema, no sólo a quienes no compartían las concepciones aperturistas, sino a los interesados en el otro tráfico.

Las impugnaciones fueron de diversos tipos. A las vinculadas a la competencia que afectaba al comercio preestablecido, como el señalado con La Habana y Lima, o incluso a la comercialización de productos regio-

19 Silva, H. A.: "La estructuración del comercio y la navegación desde el Río de la Plata a Cuba”. Anuario de Estudios Americanos, T. LI-2, Sevilla, 1994, págs. 61-73, y “Comercio y tráfico desde el Río de la Plata a Cuba (1796-1814)”. Investigaciones y Ensayos, N. 44, Buenos Aires, 1994.

20 AGI, Buenos Aires, 346.

21 Mariluz Urquijo, J. M.: El Virreinato del Río de la Plata en la época del Marqués de Avilés (1799-1801), Buenos Aires, 1964, pág. 129. 
nales como los aguardientes cuyanos, se sumaron las imputadas al propio tráfico con colonias extranjeras. Las ilegalidades que podían cometerse a su amparo y la extracción de metálico, aparecen como imputaciones fundamentales para denostar el sistema. Situación que es más comprometida al mostrarse, desde un principio, la existencia de una balanza comercial desfavorable, que debía llevar necesariamente a la extracción de metálico hacia las colonias portuguesas. Observaciones que, como hemos visto, también habían recaído sobre el comercio negrero.

En julio de 1798, el virrey Olaguer Feliú trataba de tener una visión integral del comercio con Brasil, pero sólo consiguió un informe limitado al puerto de Montevideo, debido a que "por sus muchas ocupaciones", el administrador de la aduana porteña, firme defensor del aperturismo, no lo había podido elaborar.

El hecho de no poder registrar los movimientos navieros entre Brasil y Buenos Aires, tal como lo indica el mismo virrey, relativiza los resultados de estos datos estadisticos; sin embargo estimo que igualmente son significativos del giro, particularmente si tenemos en cuenta que los embarques de carnes se hacían básicamente en la Banda Oriental.

El movimiento de entradas y salidas de barcos destinados al comercio con colonias extranjeras, producido en el puerto de Montevideo hasta finalizar 1797, nos muestra un tremendo desfase entre los valores de los productos exportados y los ingresados. Seis (5 zumacas y una corbeta), salían con destino a colonias extranjeras, conduciendo productos por valor de 23.782 pesos, entre los que se incluyen 5.900 de elementos destinados a la isla de Mauricio. Como contrapartida entraban otros seis navíos (5 zumacas y un bergantín), con importaciones evaluadas en 133.270 pesos.

Las exportaciones hacia Brasil estaban compuestas por 3.360 quintales de carnes saladas, 1.905 quintales de harina flor, 120 quintales de velas, 300 arrobas de frutas secas, 400 docenas de badanas y 237 pieles finas. Por su parte, las importaciones registraban 283 cajas, y 5.556 1/2 arrobas de azúcar, pudiéndose señalar que una sola zumaca aportaba 4.000@. Calculado el contenido de cada caja, segun información de Río de Janeiro, en 40 arrobas, el ingreso fue de 16.876 1/2 @ de azúcar.22 Paralelamente entraban por la aduana de Montevideo 443 pipas de aguardiente y 427 sacos de arroz, además de almidón, cera, café y añil; a los que se sumaban 51 negros esclavos, introducidos por Tomás A. Romero y Antonio Sar. ${ }^{23}$

22 Santos, C. M. dos: Relaçoes comerciais..., pág. 168.

23 AGI, Buenos Aires, 124. 
Es importante señalar, tanto para la comprensión de los datos expuestos, como de la puesta en marcha y mantenimiento del comercio con colonias extranjeras que, tal como ocurriera en momentos de aplicarse el Reglamento de Libre Comercio, otra contienda había puesto nuevos ingredientes a la implementación del sistema. La guerra con Gran Bretaña, desatada en 1796, había sacudido las bases del intercambio imperial español y provocado fuertes transformaciones en el tráfico colonial. Tanto la acción de la armada inglesa como la de los corsarios, afectaron duramente al comercio de ultramar. Cercaron los puertos y dieron lugar a un fuerte control en las más importantes rutas. El comercio colonial que había tenido un singular impulso en los años anteriores al rompimiento, recibió un duro golpe al firmarse con Francia, el 19 de agosto de 1796, el tratado de San Ildefonso. El cambio de frente efectuado por España, acarreó a su movimiento económico una de las situaciones más críticas vividas hasta entonces. Una brusca caída de los niveles de exportación e importación afectó al Río de la Plata no sólo en el orden económico, sino incluso en el político y en el social. La caída de las importaciones trajo un importante aumento en los precios en mercancías que incluso llegaban a desaparecer del mercado local, mientras la producción regional quedaba paralizada en los puertos de embarque. Situación que tampoco dejó de afectar al Brasil, particularmente por la presencia de corsarios franceses.

Por entonces, España debió buscar vías colaterales para paliar los efectos de la acción británica en los mares, vivificando el comercio, por lo que el 18 de noviembre de 1797, la Corona permitía "como recurso extraordinario" que se hicieran expediciones en buques neutrales desde puertos españoles o extranjeros que mantuvieran neutralidad. Determinación real que, combinada con las dos anteriores - libertad de tráfico negrero y comercio "por via de ensayo" con colonias extranjeras- permitió que, además de acrecentarse los vínculos con el Brasil, se abriera el Río de la Plata a un amplio tráfico internacional, en el que participaron activamente comerciantes y navieros de diversas nacionalidades:

"América — decía el administrador de la Aduana de Buenos Aires al Virrey, en julio de 1798 - prohibida de tener fábricas, falta de utensilios para la labranza y beneficio de las primeras materias, carece de las principales ropas para vestir sus habitantes. Sin aperos para poner navegables sus embarcaciones y sin muchos otros efectos que la precisan a subsistir con Europa, necesita socorrerse de todo". ${ }^{24}$

24 AGI, Buenos Aires, 346. 
Las variantes en los precios del azúcar y el aguardiente, incluidos entre los "efectos de mayor consumo", muestran con claridad el incentivo que se produce para incrementar las importaciones del Brasil y, consecuentemente, tender a afianzar el nuevo sistema. ${ }^{25}$

\begin{tabular}{lccc} 
& & \multicolumn{2}{c}{ Precios (en pesos) } \\
\cline { 3 - 4 } Artículo & Medida & En tiempo de paz & 1797 \\
\hline Azúcar & arroba & 4 & 5 a 5 1/2 \\
Azúcar & arroba & $31 \frac{1}{4}$ & 4 a 4 11/2 \\
Aguardiente de España & barril & 17 & 24 a 28 \\
Aguardiente de caña* & barril & 12 & 16 a 18 \\
* Proveniente de Brasil & & &
\end{tabular}

En poco tiempo, tanto como consecuencia de la implementación de medidas promotoras de la producción y del comercio, como del enfrentamiento de una coyuntura internacional difícil, producida por la guerra de 1796, el tráfico con el Brasil — pese a acaloradas críticas locales - se fue consolidando. Las actitudes gubernamentales tendentes a promover por un lado la incorporación de mano de obra esclava y por otro el desarrollo de un mayor intercambio, a través del comercio con colonias extranjeras, debieron ahora conjugarse con los requerimientos impuestos por una contienda que, desde el punto de vista económico, fue desastrosa para el Imperio Español.

Si bien el objetivo de este trabajo está dirigido a estudiar el establecimiento formal de vínculos comerciales sobre visos de legalidad entre el Río de la Plata y el Brasil, acotándonos al período 1791-1797, es interesante señalar la continuidad que se produce en el sistema. De allí que aunque cuestiones como las disputas en torno al comercio con el Brasil o las variantes en el movimiento económico — como la producida por la "guerra de las naranjas"- merezcan un tratamiento especial, sea interesante insertar algunos conceptos contrarios al mantenimiento de tales relaciones que ejemplifican la consistencia de las resoluciones tomadas en el período que nos ocupa.

25 AGN, IX-4-7-5. 
Cuando en 1799 se discuten en el Consulado los alcances de la real orden inhibitoria del comercio con neutrales, el prior Martín de Alzaga, señalaba, aunque sin conseguir su objetivo, que "si el espíritu es remediar los males de la extracción de plata y demás fraudes, no de otra suerte puede conseguirse este fin que cortando toda comunicación con colonias extranjeras". ${ }^{26}$ Por entonces se estaba en plena guerra, pero además podemos observar cómo aun en el interregno de paz 1802-1804, se mantenía la vigencia del tráfico con colonias extranjeras, con disputas que alcanzaban incluso a las más altas autoridades. De allí que el virrey del Pino, riguroso partidario de las estructuras tradicionales, impugnara el sistema indicando que no se había beneficiado la agricultura local, mientras que la balanza comercial mostraba la preponderancia de los retornos de mercaderías foráneas. A su entender, todo se movía en un plano de ilegalidad, porque aun los teóricos beneficiarios

\begin{abstract}
"prestan infielmente su nombre para retornar a su sombra en el valor de los frutos que se suponen cambiados, crecidos intereses extranjeros cuyo producto, en la mayor parte, vuelve a sus manos en dinero contante extraído por medios más sagaces, burlando la actividad del gobierno y diligencias del resguardo; además de la proporción de ejercitar el contrabando de efectos europeos, como se ejecuta sin cesar, con gravísimo daño de nuestro comercio nacional, sin que baste precaverlo la mayor vigilancia y energía, por la facilidad del trasbordo en este Río de la Plata, o desembarco en sus dilatadas y desiertas costas a donde por falta de auxilios no llega el celo del resguardo, presentándose después los buques en estos puertos con sólo los frutos permitidos al cambio". ${ }^{27}$
\end{abstract}

Sin duda las acusaciones emanadas de la más alta autoridad virreinal eran serias. La extracción de metálico y la ilegalidad seguían siendo los argumentos principales de los detractores. No obstante, sin entrar a analizar en este momento los alcances y connotaciones de los mismos, considero que es justamente esa seriedad y el nivel de quien las expresa, un elemento sustancial para apreciar hasta qué punto fue impugnado este tráfico. Situación que, asimismo, nos permite observar como, luego de ponerse la piedra fundamental con la libertad de tráfico negrero, aquel sistema de relaciones económicas con colonias extranjeras iniciado "por vía de ensayo" en 1795 y ratificado expresamente para fomentar el comercio con el Brasil, con un "por ahora" del rey, en 1796, sentó las bases de una relación comercial estable.

26 Mariluz Urquijo, J. M.: El Virreinato..., pág. 137.

27 Heredia, E. A.: Cuando Sarratea se hizo revolucionario, Buenos Aires, 1986, Apéndice documental, pág. 91. 
Por su situación geográfica, por su condición de marginalidad dentro del mundo hispano, por interés o necesidad, el Río de la Plata, desde el siglo XVI había estado conectado económicamente con el Brasil. Por diversas vías se concretó la introducción de mercancías y esclavos que condujeron hasta la zona altoperuana. Si bien por parte de la Corona Hispana se dieron autorizaciones especiales para establecer relaciones comerciales, éstas tuvieron características limitadas, obedeciendo, por lo general, al deseo de paliar situaciones o mostrar algun tipo de favorecimiento personal. Frente a esto, a través del Brasil, el mundo lusitano y, particularmente su aliado británico, encontraron vías para establecer un importante tráfico, favorecidos particularmente por la instalación, desde 1680, de la Colonia del Sacramento. Enclave portugués en la margen oriental del Río de la Plata que, si bien sufrió los vaivenes de la política internacional, con ocupaciones y reintegros, cimentó uno de los comercios ilícitos más florecientes y amplios de América. Ubicada frente a Buenos Aires, en una zona donde las autoridades españolas no podían - o no querían - ejercer patrullajes permanentes y efectivos, la Colonia del Sacramento se constituyó desde su fundación, en un gran almacén destinado al contrabando. La puerta portuguesa era adecuada para la introducción de artículos propios y ajenos. Tal es el caso de productos de la tierra y esclavos, a los que se sumaban las manufacturas británicas y otras que en calidad de intermediarios, traficaban los ingleses desde las más diversas partes del mundo. No son alejados de la realidad los conceptos de John Lynch, cuando señala que "lo que Jamaica significaba para el Caribe el Sacramento significaba para el Río de la Plata". ${ }^{28}$

La creación del Virreinato rioplatense, con la consecuente toma final de la Colonia del Sacramento, significó un duro revés para el contrabando, pero no por ello produjo el rompimiento de lazos mercantiles con el Brasil. Ya a través de la extensa frontera, o del empleo de artilugios como las arribadas forzosas, se hicieron presentes en los mercados regionales; a lo que se sumaron autorizaciones como las dadas frente a las necesidades producidas por los conflictos bélicos. De allí que el planteamiento expuesto en el presente trabajo no deba confundirse con la instalación de un comercio que ya tenía siglos de subsistencia y experiencia, sino con el establecimiento de disposiciones legales que, aunque también escondieron muchos fraudes, fueron determinantes para realizar un fluido y continuo tráfico intercolonial.

28 Lynch, J.: Administración colonial española, 1782-1810. El sistema de intendencias en el Virreinato del Río de la Plata, Buenos Aires, 1967, pág. 38. 